\title{
Prognostic validation of the WHO 2010 grading system in pancreatic insulinoma patients
}

\author{
L. WANG, M. YANG, Y. ZHANG, S. XU, B. L. TIAN* \\ Hepatobiliopancreatic Surgery, West China Hospital, Sichuan University, Chengdu, China \\ *Correspondence: 328282003@qq.com
}

Received August 2, 2014 / Accepted December 3, 2014

\begin{abstract}
The purpose of this study was to evaluate the prognostic potential of the World Health Organization (WHO) 2010 grading system in patients with pancreatic insulinomas. This was a retrospective study that analyzed the overall survival of 85 pancreatic insulinoma patients treated at our Institute between May 2002 and March 2013. The mean age of our patient cohort was $44.26 \pm 13.82$ years, with the gender split at 30 males and 55 females. Median survival time of the cohort, post-surgery, was $100.23 \pm 18.18$ months. Among the 85 patients, histopathological analyses revealed 52 Low Grade (G1) neuroendocrine tumors (NET), 23 Intermediate Grade (G2) NET, and 10 High Grade (G3) Neuroendocrine carcinomas (NEC) according to the WHO 2010 grading classification. Significant difference for overall survival was observed between the NET G1 and NEC G3 groups $(\mathrm{P}<0.01)$, and the NET G2 and NEC G3 groups $(\mathrm{P}<0.019)$. In addition, our data showed that overall survival was significantly correlated with the European Neuroendocrine Tumor Society (ENETS) tumor-node-metastasis (TNM) staging system, and in multivariate analysis, the diameter of tumor was found to be significantly correlated with survival $(\mathrm{P}=0.038)$. These findings provide additional validation for the prognostic value of using the WHO 2010 grading system, specifically with regard to pancreatic insulinomas.
\end{abstract}

Key words: insulinoma, prognosis, WHO grading, enucleation, octreotide

Insulinomas are one of the most common pancreatic neuroendocrine tumors (PNETS), with an incidence of 0.4 - 7 per million population per year [1]. However, autopsy studies have reported higher incidences $(0.8-10 \%)$ of PNETS, suggesting that most of the disease actually goes undiagnosed $[2,3]$, and advancements in diagnostic techniques have led to increased diagnoses of PNETS in recent years [4]. The median age of those diagnosed with insulinoma is 50 years, with a slight predilection for females [5], and greater than $90 \%$ of insulinomas are thought to occur sporadically, typically presented as solidary, benign, and encapsulated lesions $[6,7]$.

While pharmacological agents such as octreotide, a somatostatin analog, are frequently used to control hormone related symptoms associated with insulinomas $[9,10]$, surgical intervention is the ultimate treatment of choice as it can be curative. The preferred surgical approach to remove insulinomas is enucleation, since most of them tend to be small, benign and encapsulated [11-13]. While enucleation is successful at maximizing local control of the tumor, minimizing hypoglycemic symptoms, and has a low mortality rate (less than $2 \%$ )
[11-13, 15-17], enucleation procedures do have a relatively high incidence of pancreatic fistulas (38\%) [14]. Further, enucleation is not always possible especially for PNETS that are suspected to be invasive, or tumors that are larger than $3 \mathrm{~cm}$ (particularly for those associated with the dilated pancreatic main duct) [18].

The older WHO 2004 grading system of PNETS [19] did demonstrate some value in evaluating the outcome and prognosis for insulinoma patients, but was not widely accepted owing to its limited ability to predict the biological aggressiveness, since low grade PNETS can also metastasize, and because of the many criteria that needed to be evaluated [20]. The WHO grading classification of PNETS was updated and simplified in 2010, and the update includes 4 categories of PNETS: neuroendocrine tumor G1 (NET G1), neuroendocrine tumor G2 (NET G2), neuroendocrine carcinoma G3 (NEC G3), and mixed adenoneuroendocrine carcinoma (MANEC) [21]. This classification emphasizes the integration of the mitotic count and Ki-67 labeling index to better classify the biological characteristic of these neoplasms. 
Numerous studies have reported on the prognosis associated with PNETs [22, 23]. However, studies reporting on the prognosis of insulinoma, which is the predominant type of functional PNETS, are few. This is likely due to the heterogeneity and rarity of insulinomas, especially with regard to using the new 2010 grading classifications of the World Health Organization (WHO) [21] and the Tumor-Node-Metastasis (TNM) staging system of ENETS [24]. With increasing insulinoma diagnoses in recent decades, novel approaches for the treatment of this disease are in high need. In this study, we reviewed the 10-year experience from our Institution. Our analysis included 85 consecutive patients that had resections of insulinomas, and we assessed long-term survival following surgical resection to evaluate a number of different prognostic factors, including an emphasis on the prognostic value of the updated WHO 2010 grading classifications.

\section{Patients and methods}

Patients. Patients criteria included pathological and immunohistochemical diagnosis of pancreatic insulinoma, surgically treated insulinoma by enucleation of tumor or other radical resection (e.g. distal pancreatectomy, pancreaticoduodenectomy) at the West China Hospital of Sichuan University. Exclusion criteria included absence of surgical treatment, presence of chemotherapy, diagnosis of MEN1 (Multiple Endocrine Neoplasia 1), co-existence of other types of carcinomas, and insufficient tumor tissue for histopathological analysis. None of the enrolled patients had used any diazoxide, and most (87.1\%) of them had a history of octreotide use. This study was approved by the Ethics Committee of the West China Hospital of Sichuan University.

Medical and surgical treatments. The pharmacological treatment history of patients was obtained by questionnaire or out-patient follow-up. Any history treatment course with octreotide (subcutaneous injection) was considered as having a medical history of octreotide use. Experienced medical teams in the Hepato-pancreatic-biliary department had performed all surgeries. Enucleation was the first-line surgical intervention for insulinomas with clear preoperative locations. Otherwise, insulinomas with close proximity to the pancreatic duct or involving a large portion of the pancreas underwent other radical surgeries, such as distal pancreatectomy, segment resection of pancreas, and in some rare cases, pancreaticoduodenectomy. In the earlier years of this patient cohort, a very minor number of blind pancreatic resections had been performed for tumors without a clear preoperative location.

Data collection and follow-up. From May 2002 to March 2013, we enrolled 85 patients that met the eligibility criteria. Patient data, including demographics (gender and age), surgical data (e.g. procedures, length of surgery, intraoperative findings), and pathological and immunohistochemical records were all retrospectively reviewed from medical records. Telephone follow-ups were conducted during the months of March and April, 2014. Overall survival (in months) was calculated from the date of surgery until tumor specific death or the patient's last follow-up. One patient died after surgery, and six patients could not be located for follow-up, and thus, were excluded from the survival analysis.

Tumor characteristics. Tumor characteristics (e.g. tumor size, location, surgical margin, Ki-67) were based on intraoperative and pathological findings. The updated WHO 2010 grading classifications and the ENETS 2006 TNM staging systems were both used to analyze the clinical characteristics and to assess insulinoma patients' outcome. The WHO 2010 grading classification is as follows: NET G1 (neuroendocrine tumor G1: mitotic count: $\leq 2 / 10 \mathrm{HPF}$ (high-powered fields), Ki-67: $\leq 2 \%$ ); NET G2 (neuroendocrine tumor G2: mitotic count: 2-20/10 HPF, Ki-67: 3-20\%); NEC G3 (neuroendocrine carcinoma G3: mitotic count > 20/10 HPF, Ki-67 > 20\%); MANC (Mixed Adeno and Neuroendocrine Carcinoma).

Statistical analysis. In order to evaluate the prognostic value of the WHO 2010 grading classifications, the prospectively established primary objective was to determine whether the proportion of patients with G1 or G2 insulinoma had a significantly longer survival time than those from the G3 group. The main outcome variable was the elapsed time (in months) from surgery to death. Covariates in the analysis included tumor size, type of surgery, use of octreotide or not, the WHO 2010 grading classifications and the ENETS 2006 TNM staging systems. In the survival analysis, the survival distribution for each grade (different grade of WHO 2010 grading system or the ENETS 2006 TNM staging systems) were estimated using the Kaplan-Meier method, and they were tested for equality by the log-rank test. Survival distribution was also analyzed between patients with different clinical characteristics, such as tumor size, or type of surgery. Secondly, with an emphasis on WHO 2010 grading classifications, single and multiple variates analysis with the Cox proportional hazard regression model was conducted with age, sex, tumor size, use of octreotide, type of surgery, and importantly the WHO 2010 grading classifications as prognostic factors. Differences with a two-sided $\mathrm{P}$ value less than 0.05 was considered statistically significant. Statistical analyses were performed using SPSS 21.0 statistical software.

\section{Results}

Patient and tumor characteristics. Characteristics of the pancreatic insulinoma patients that had undergone pancreatic surgery at the West China Hospital of Sichuan University between May 2002 and March 2013 are presented in Table 1. In this cohort, the disease had a predilection for females, with a sex ratio of 6:11 (males: females), and patients had a mean age of $44.26 \pm 13.82$ years. The majority of patients had a history of subcutaneous octreotide (87.1\%), and been surgically treated by enucleation (68.2\%). In addition, tumors tended to be relatively small $(1.88 \pm 1.42 \mathrm{~cm})$, with a nearly similar proportion of location in the head, body and tail of pancreas $(32.9 \%, 35.3 \%, 31.8 \%$ 
Table 1. Patient and Tumor Characteristics

\begin{tabular}{|c|c|}
\hline Classification & mean $\pm \mathrm{SD} /$ proportion \\
\hline Age & $44.26 \pm 13.82$ \\
\hline \multicolumn{2}{|l|}{ Gender } \\
\hline Male & $30(35.3 \%)$ \\
\hline Female & $55(64.7 \%)$ \\
\hline \multicolumn{2}{|l|}{ Use of octreotide } \\
\hline Yes & $74(87.1 \%)$ \\
\hline No & $11(12.9 \%)$ \\
\hline \multicolumn{2}{|l|}{ Surgical Technique } \\
\hline Enucleation & $58(68.2 \%)$ \\
\hline Radical Surgery & $27(31.8 \%)$ \\
\hline \multicolumn{2}{|l|}{ Tumor } \\
\hline Diameter $(\mathrm{cm})$ & $1.88 \pm 1.42$ \\
\hline \multicolumn{2}{|c|}{ Tumor location in pancreas } \\
\hline Head & $28(32.9 \%)$ \\
\hline Body & $30(35.3 \%)$ \\
\hline Tail & $27(31.8 \%)$ \\
\hline \multicolumn{2}{|c|}{ New grading classification of WHO 2010} \\
\hline G1 & $52(61.2 \%)$ \\
\hline G2 & $23(27.1 \%)$ \\
\hline G3 & $10(11.8 \%)$ \\
\hline \multicolumn{2}{|l|}{$T N M$} \\
\hline I & $51(60 \%)$ \\
\hline II & $23(27.1 \%)$ \\
\hline III & $7(8.2 \%)$ \\
\hline IV & $4(4.7 \%)$ \\
\hline
\end{tabular}

respectively). Clinical stage I, II, III, and IV was defined in 51, 23, 7 and 4 patients, respectively, using the TNM staging system of the ENETS (2006). The WHO 2010 grading classification was possible for all patients, and the distribution of tumors was as follows: 52 NET G1, 23 NET G2, and 10 for NEC G3.

Table 2. The statistical analysis of each system

\begin{tabular}{lccc}
\hline Classification & $\begin{array}{c}\text { Median survival } \\
\text { time(month) }\end{array}$ & $95 \%$ CI & ** \\
\hline WHO 2010 G1 & $-^{*}$ & $-^{*}$ & \\
(Fig.1) G2 & 108.80 & $55.78-161.82$ & \\
G3 & 38.00 & $13.55-62.45$ & \\
TNM I & $-^{*}$ & $-*$ & $* * *$ \\
(Fig.2) II & 78.34 & $57.99-98.68$ & \\
III & 59.00 & $7.43-110.58$ & \\
IV & 30.23 & $17.39-43.08$ & \\
Diameter $<2 \mathrm{~cm}$ & 108.80 & $91.21-109.39$ & 0.016 \\
(Fig.3) $\geq 2 \mathrm{~cm}$ & 78.1 & $45.96-110.24$ & \\
\hline
\end{tabular}

* $>50 \%$ of patients were alive at last follow-up in this subgroup; the estimated median survival time was unavailable.

** G1 vs. G2, $P=0.423$; G1 vs. G3, $P<0.01 ; \mathrm{G} 2$ vs G3, $P=0.019$.

$* * *$ In the ENETS 2006 TNM staging system, only the difference between the estimated survival time of stage III and IV was not significant. The exact $P$ values are presented in the footnotes of Figure 2 .
Survival analysis. The follow-up periods ranged from 12 to 130 months post-surgery, and 14 of 78 patients died subsequently after recurrence. Our survival function estimates showed that median survival time of our cohort was $100.23 \pm$ 18.18 months. In terms of the WHO 2010 grading classification (Figure 1, Table 2), the Kaplan-Meier estimated survival time for patients in the NET G1 vs. NEC G3, and NET G2 vs. NEC G3 groups, was statistically different $(\mathrm{P}<0.01,0.019$; respectively), whereas there was no significant difference between the NET G1 and NET G2 groups $(\mathrm{P}=0.423)$. The TNM stage system of the ENETS was also significantly correlated with overall survival (Figure 2, Table 2). Notably, the survival time of patients in stage I was statistically longer than those in stages II $(\mathrm{P}=0.045)$, III $(\mathrm{P}<0.005)$ and IV $(\mathrm{P}<0.005)$. Also, patients in stage II obtained statistically better survival than those in stages III $(\mathrm{P}<0.01)$ and IV $(\mathrm{P}<0.005)$, while no notable differences were found between stages III and IV $(\mathrm{P}=0.099)$. Although, insulinoma had a predilection for females, the survival of females in the cohort had no significant difference from that of males $(\mathrm{P}=0.771)$. Patients with larger tumors (i.e. $\geq 2 \mathrm{~cm}$ ) had a significantly shorter survival time than patients with smaller tumors $(<2 \mathrm{~cm})(\mathrm{P}=0.016)$ (Figure 3, Table 2). As the log-rank test revealed, the overall survival between patients who had undergone more radical surgical procedures, and those who underwent enucleation, was without significant difference. There was also no notable difference between patients that had been treated with octreotide to those that were not treated with octreotide. However, in the 10 NEC G3 patients, the survival time of the more radical surgery group was significantly longer than that of the enucleation group (69.43 months vs. 30.23 months; $\mathrm{P}=0.036$ ).

Outcomes using single and multiple variates. The $\mathrm{WHO}$ 2010 grading classification, age, sex, type of surgery, use of octreotide, and tumor diameter were used as single covariates in our Cox regression model. Age and sex were not predictive of survival outcome ( $\mathrm{P}=0.60$, and $\mathrm{P}=0.77$, respectively). In addition, having undergone curative radical surgery, or the use of octreotide were also not significant with regard to longer survival time $(\mathrm{P}=0.292$, and $\mathrm{P}=0.577$, respectively). However, having a larger tumor $(\geq 2 \mathrm{~cm})$ was significantly associated with poorer survival time $(\mathrm{P}=0.020)$, and patients with G1 or G2 insulinomas experienced significantly greater survival times as compared to patients with G3 insulinomas $(\mathrm{P}<0.01)$.

For the multivariate analysis, covariates, which included WHO 2010 grading classification, age, sex, type of surgery, use of octreotide, and tumor diameter, were entered in our Cox regression to probe potential prognostic factors of patients who had undergone surgery and had a diagnosis of insulinoma (Table 3). Interestingly, we found that tumor diameter was significantly associated with survival $(\mathrm{P}=0.038)$, as were the WHO 2010 grading classifications. Specifically, patients with G1 and G2 tumors survived longer than those with G3 tumors, when the effects of the other prognostic indicators were controlled for in our analysis $(\mathrm{P}<0.01)$. 


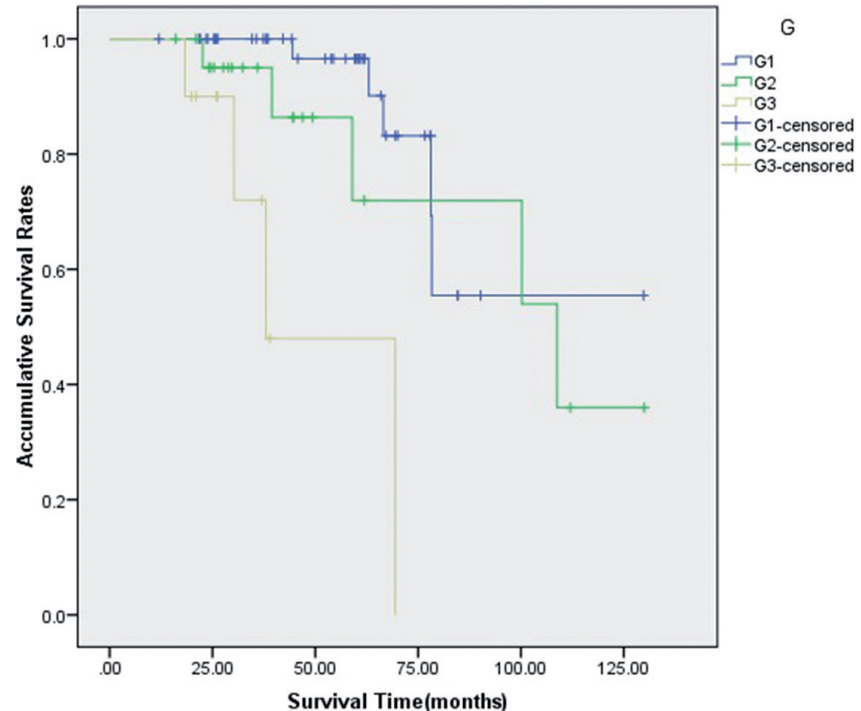

Figure 1. Comparison of Cumulative Survival in patients with PNETS using the WHO grading classifications. The survival times for patients between NET G1 and NEC G3, NET G2 and NEC G3 were statistically different $(P<0.01$, and $P=0.019$, respectively $)$, whereas survival time between NET G1 and NET G2 was not statistically significantly different $(P=0.423)$.

\section{Discussion}

To the best of our knowledge, a number of studies have investigated the prognosis of PNETS using the WHO 2010 grading classification. However, a minority of studies have employed this classification to evaluate the prognosis of pancreatic insulinoma, which is the main functional type of PNETS. Although insulinomas are considered a rare type of neuroendocrine tumor, they are the most common functional PNETS, with an increasing incidence in recent years [1, 4]. Further, data suggest that insulinomas tend to be more common

Table 3. Multiple Cox regression of age, sex, surgical technique, tumor diameter, and updated WHO 2010 grading classification

\begin{tabular}{lll}
\hline Variable & P value & hazard ratio (95\% CI) \\
\hline Age at surgery & 0.773 & $1.19(0.37-3.81)$ \\
Sex & 0.988 & $1.01(0.25-4.11)$ \\
Surgery & 0.108 & $0.23(0.04-1.39)$ \\
Use of octreotide & 0.626 & $1.413(0.35-5.68)$ \\
Tumor Diameter & 0.038 & $3.46(1.04-11.18)$ \\
Updated grading classi- & $<0.01$ & $31.19(4.94-196.93)$ \\
fication of WHO 2010 & & \\
\hline
\end{tabular}

All covariates are binary variables. Age at surgery ( 0 for age $\leq 45$ years; 1 for age $>45$ years); sex ( 0 for female; 1 for male); surgery ( 0 for enucleation; 1 for radical surgical technique); use of octreotide ( 0 no octreotide use; 1 any history of octreotide use); tumor diameter ( 0 for tumor diameter $<2 \mathrm{~cm}$; 1 for tumor diameter $\geq 2 \mathrm{~cm}$ ); updated WHO 2010 grading classification (0 for insulinoma of G1 and G2 NET; 1 for G3 NEC).

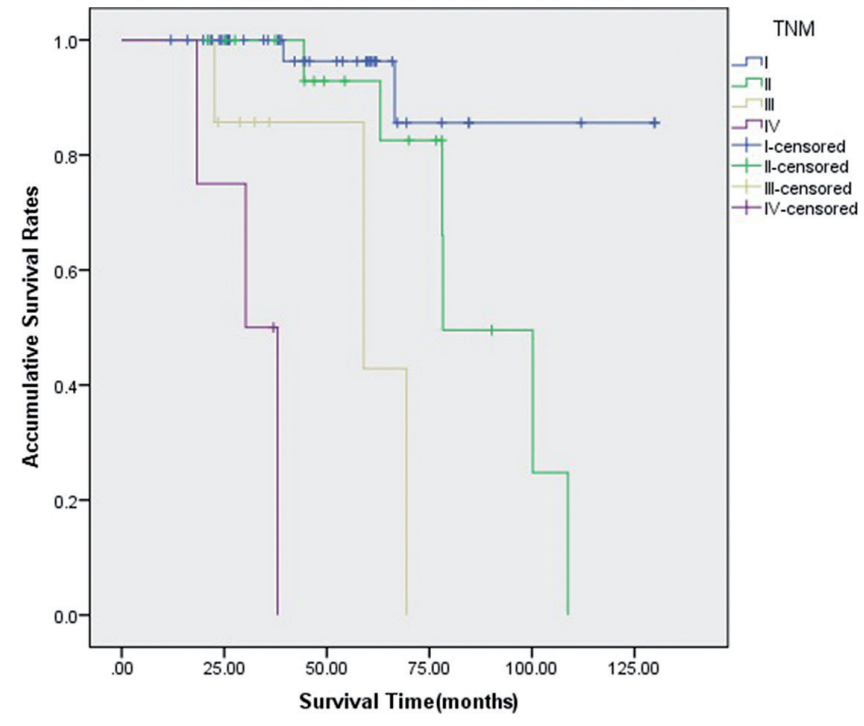

Figure 2. Comparison of Cumulative Survival of Patients with PNETS at different stages. The survival time of patients in stage I was statistically longer than those in stage II, III and IV $(P=0.045,<0.005$, and $<0.005$, respectively). Also, patients in stage II obtained statistically longer survival than those in stages III and IV $(P<0.01$, and $<0.005$, respectively), while no notable differences were found between stages III and IV $(P=0.099)$.

in females than males, with most insulinomas occurring in the fifth decade of life [5]. In this present work, insulinomas were found to be approximately 1.8 times more common in women than men, and the insulinomas were diagnosed at a median age of $44.26 \pm 13.82$ years. Most pancreatic insulinomas are

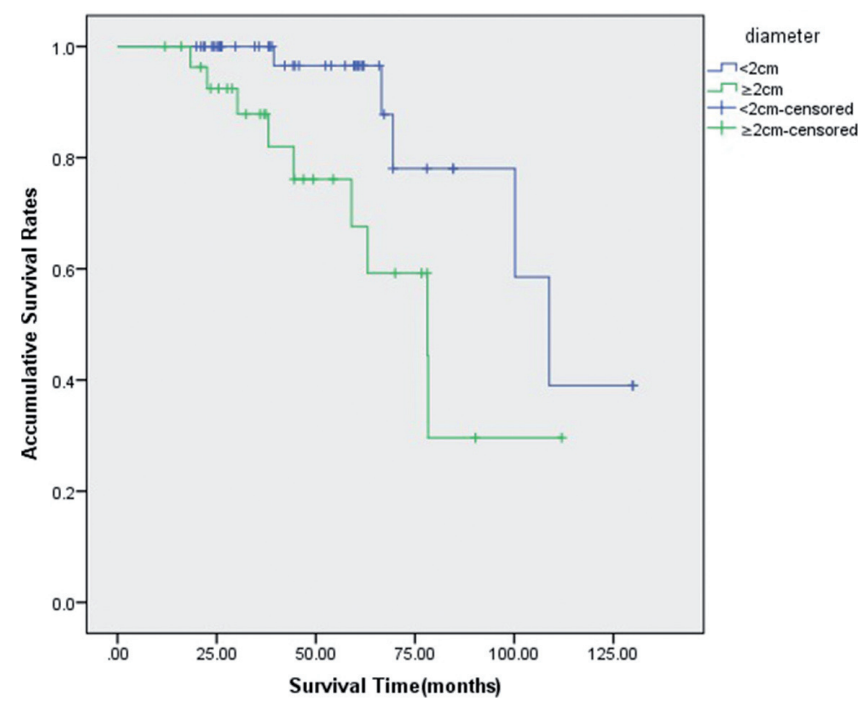

Figure 3. Comparison of Cumulative Survival among insulinoma patients with varying tumor sizes. Patients with larger tumors $(\geq 2 \mathrm{~cm})$ had a significantly shorter survival time than those with smaller tumors $(<2 \mathrm{~cm})$ $(P=0.016)$. 
also known to be singular, benign, small $(<2 \mathrm{~cm})$, and slow growing [6-7], with the caudal location considered by some to be the most frequent tumor site $[25,26]$. According to our data, the majority of the insulinomas from our patient cohort were small $(1.88 \pm 1.42 \mathrm{~cm}) \mathrm{G} 1$ and G2 tumors $(88.3 \%)$, with a slight predilection for location in the body and tail of the pancreas (67.1\%).

Somatostatin analogs, such as octreotide, have been used in PNETS for symptom control in functioning tumors [27]. Although two randomized placebo-controlled trials demonstrated that prophylactic use of somatostatin analogs do not reduce the incidences of pancreatic fistulas or total postoperative complications after pancreatic resection $[29,30]$, they can inhibit the secretion of insulin in $40-60 \%$ of insulinomas by virtue of their binding to somatostatin receptors on tumor cells [28-30]. Unfortunately, compared with other PNETS, the low expression of somatostatin receptors on pancreatic insulinomas have limited their utility in treating these tumors [31]. In the present study, we have demonstrated that in patients with a history of octreotide use had similar survival times relative to those that had never used somatostatin analogs, and in addition, there were no statistically significant findings in the univariate or multivariate analyses. However, due to the retrospective nature of our study, and the small proportion of patients with no history of octreotide use (i.e. 12.9\%), we are unable to make definitive conclusions on the prognostic value of octreotide for patients with insulinoma.

Surgery is the only curative treatment for pancreatic insulinoma. Based on the nature of this tumor, enucleation is the preferred surgical technique, and is associated with low morbidity and mortality rates [11-13, 18]. For the majority of patients with a diagnosis of insulinoma, enucleation effectively relieves symptoms related to hormone secretion, and prolongs patient survival time [32, 33]. However, for patients with a NEC (e.g. G3 insulinoma), more radical curative surgical techniques are often advised [18]. In this 85 patient cohort, which included insulinomas of different grades, 58 patients had undergone enucleation of their insulinoma, while 27 had undergone more radical surgeries (e.g. partial pancreatic resection, pancreaticduodenectomy). With regard to survival time between the two groups, we found no statistical difference. In addition, a more radical surgery was not a significant predictor in the multivariate analysis. However, for the group of 10 patients with NEC G3 tumors, the median survival time of the more radical surgery group was significant longer than that of the enucleation group (69.43 months vs. 30.23 months; $\mathrm{P}=0.036$ ). Thus, our limited data suggest that more radical surgeries should be the preferred intervention for patients with G3 insulinomas, which are often detected by preoperative biopsy or intraoperative suspicion of malignancy (e.g. infiltrating lymph invasion, pancreatic duct dilation).

A high Ki-67 labeling index and high mitotic count have been described as the most consistent prognostic factors for poor outcome of PNETS [34]. Indeed, the current WHO grading classification is based on these two factors only (in contrast to the WHO 2004 guidelines which included additional criteria). In the present study, the survival of the G3 group was significantly lower than that of G1 and G2 groups. Further, the WHO 2010 grading classification was a significant prognostic factor both in our univariate and multivariate analyses. However, the grading level of Ki-67 between NET G1 (neuroendocrine tumor G1: mitotic count: $\leq 2 / 10 \mathrm{HPF}$, Ki67: $\leq 2 \%$ ), and NET G2 (neuroendocrine tumor G2: mitotic count: 2-20/10HPF, Ki-67: 3\%-20\%) remains controversial. Bosman et al, have indicated that the long-time survival between patients with G1 and G2 tumors would be significantly different as a result of increasing the Ki-67 level (between G1 and G2) from $2 \%$ to $5 \%$ [21]. As noted earlier, by combining the mitotic count and Ki-67 positive rate, we evaluated the surgical outcome of insulinoma by the updated WHO grading system and evaluated its prognostic value, in which we concluded that, patients with insulinomas of NET G1 and NEC G2 gained statistically better survival rates than those of NEC G3 ( $\mathrm{P}<0.01$, and $\mathrm{P}=0.019$, respectively), whereas survival between NET G1 and NET G2 was not significantly different $(\mathrm{P}=0.423)$. Likewise, the previous WHO 2004 classification discriminated between the low- and high-grade malignant PNETS, but did not differentiate further prognosis of low and intermediate malignant PNETS [35]. Therefore, the prognostic value of Ki-67 was a definite, one while the level between G1 and G2 may require future adjustments.

Notably, due to some incomplete data, we were unable to perform a direct comparison between the WHO 2004 and WHO 2010 classifications. However, the results from our study provide validation for the prognostic value of the updated WHO 2010 grading classification system, and importantly, we were able to validate the WHO 2010 system using fewer data points than would have been required when using the WHO 2004 system. We view this as a significant advance, since the simplified WHO 2010 system represents a more "userfriendly" system that is potentially easier to implement and interpret for clinicians (i.e. WHO 2010 classification system relies only on mitotic count and proliferation index) compared to the 2004 version.

Although the ENETS 2006 TNM stage system is being widely used for most types of cancers, and is well-accepted by the surgical medical community, the new WHO 2010 grading system (which depends on more detailed and timeconsuming pathological examination) reflected the biological aggressiveness better as compared with the ENETS 2006 TNM stage system. Overall, both of these two systems have their advantages and disadvantages, and they depend on the pathological and clinical characteristics of tumor, respectively. It is suggested that surgeons should combine both of them, in a complementary approach, for the evaluation of the prognosis of insulinoma.

In addition, tumor diameter was found to be a significant prognostic factor both in our univariate and multivariate analyses. A number of possibilities may explain these results. First, removal of larger tumors may result in greater pancreatic 
surgical wounds, and thus, a higher risk of injury to the pancreatic duct, which could be detrimental to survival. Moreover, the new WHO 2010 classification of tumors of the digestive system considers all insulinomas $\geq 0.5 \mathrm{~cm}$ as malignant tumors [19]. Lastly, larger tumors are thought to be associated with more aggressive forms of PNETS [36, 37].

In conclusion, systematic clinical-pathological assessment and follow-up validate the utility of the updated WHO 2010 grading classifications for the prognosis of pancreatic insulinoma. Nonetheless, the cut-off levels for Ki-67 between the G1 and G2 categories may potentially need adjustment, as mentioned earlier. As evidenced by numerous studies, ENETS 2006 TNM staging systems have also been shown to have prognostic value, and importantly, these two grading systems may complement each other when used together when making clinical decisions. Also, while enucleation is the surgical intervention of choice for most insulinoma patients, more radical surgeries are often necessary for patients with G3 insulinomas. Overall, our study confirms that insulinomas with larger tumor diameters typically result in poorer survival outcomes, and that the prognostic value of the WHO 2010 grading classification has been validated with regard to overall survival of pancreatic insulinoma patients. These data provide rationale for conducting additional studies in larger and diverse cohorts.

\section{References}

[1] HALFDANARSON TR, RUBIN J, FARNELL MB, GRANT CS, PETERSEN GM. Pancreatic endocrineneoplasms: epidemiology and prognosis of pancreatic endocrine tumors. Endocr Relat Cancer 2008; 15: 409-427. http://dx.doi. org/10.1677/ERC-07-0221

[2] KIMURA W, KURODA A, MORIOKA Y. Clinical pathology of endocrine tumors of the pancreas. Analysis of autopsy cases. Dig Dis Sci 1991; 36: 933-942. http://dx.doi.org/10.1007/ BF01297144

[3] GRIMELIUS L, HULTQUIST GT, STENKVIST B. Cytological differentiation of asymptomatic pancreatic islet cell tumours in autopsy material. Virchows Arch A Pathol Anat Histol 1975; 365: 275-288. http://dx.doi.org/10.1007/BF00471177

[4] YAO JC, HASSAN M, PHAN A, DAGOHOY C, LEARY C, et al. One hundred years after „carcinoid“: epidemiology of and prognostic factors for neuroendocrine tumors in 35,825 cases in the United States. J Clin Oncol 2008; 26: 3063-3072. http://dx.doi.org/10.1200/JCO.2007.15.4377

[5] MARX S, SPIEGEL AM, SKARULIS MC, DOPPMAN JL, COLLINS FS, et al. Multiple endocrineneoplasia type1: clinical and genetictopics. Ann Intern Med 1998; 129: 484-494. http:// dx.doi.org/10.7326/0003-4819-129-6-199809150-00011

[6] CALLENDER GG, RICH TA, PERRIER ND. Multiple endocrine neoplasia syndromes. Surg Clin North Am 2008; 88(4): 863-895. http://dx.doi.org/10.1016/j.suc.2008.05.001

[7] DEMEURE MJ, KLONOFF DC, KARAM JH, DUH QY, CLARK OH. Insulinomas associated with multiple endocrine neoplasma type I: the need for a different surgical approach. Surgery 1991; 110: 998-1005.
[8] SERVICE FJ, MCMAHON MM, O'BRIEN PC, BALLARD DJ. Functioning insulinoma-incidence, recurrence and long-term survival of patients: a 60-year study. Mayo Clin Proc 1991; 66: 711-719. http://dx.doi.org/10.1016/S0025-6196(12)62083-7

[9] JENSEN RT, BERNA MJ, BINGHAM DB, NORTON JA. Inherited pancreatic endocrine tumor syndromes: advances in molecular pathogenesis, diagnosis, management, and controversies. Cancer 2008; 113: 1807-1843. http://dx.doi. org/10.1002/cncr.23648

[10] GORDEN P, COMI RJ, MATON PN, GO VL. NIH conference. Somatostatin and somatostatin analogue (SMS201-995) in treatment of hormone-secreting tumors of the pituitary and gastrointestinal tract and non-neoplastic diseases of the gut. Ann Intern Med 1989; 110: 35-50. http://dx.doi. org/10.7326/0003-4819-110-1-35

[11] PARK BJ, ALEXANDER HR, LIBUTTI SK, HUANG J, ROYALTY D, et al. Operative management of islet-cell tumors arising in the head of the pancreas. Surgery 1998; 124: 1056-1061. http://dx.doi.org/10.1067/msy.1998.92171

[12] SWEET MP, IZUMISATO Y, WAY LW,CLARK OH, MASHARANI U, et al. Laparoscopic enucleation of insulinomas. Arch Surg2007; 142: 1202-1204. http://dx.doi.org/10.1001/ archsurg.142.12.1202

[13] SARMIENTO JM, QUE FG, GRANT CS, THOMPSON GB, FARNELL MB, et al. Concurrent resections of pancreatic islet cell cancers with synchronous hepatic metastases: outcomes of an aggressive approach. Surgery 2002; 132: 976-982. http:// dx.doi.org/10.1067/msy.2002.128615

[14] Fernandez-Cruz L, Blanco L, Cosa R, Rendon H. Is laparoscopic resection adequate in patients with pancreatic neuroendocrine tumors? World J Surg 2008; 32: 904-917. http://dx.doi.org/10.1007/s00268-008-9467-2

[15] MCCOLLUM AD, KILKE MH, RYAN DP, CLARK JW, SHULMAN LN, et al. Lack of efficacy of streptozocin and doxorubicin in patients with advanced pancreatic endocrine tumors. Am J Clin Oncol 2004; 27: 485-488. http://dx.doi. org/10.1097/01.coc.0000135343.06038.eb

[16] PHAN AT, YAO JC, EVANS DB. Treatment options for metastatic neuroendocrine tumors. Surgery2008; 144: 895-898. http://dx.doi.org/10.1016/j.surg.2008.10.003

[17] MADOFF DC, GUPTA S, AHRAR K, MURTHY R, YAO JC. Update on management of neuroendocrine hepatic metastases. J Vasc Interv Radiol 2006; 17: 1235-1249. http://dx.doi. org/10.1097/01.RVI.0000232177.57950.71

[18] KUNZ PL, REIDY-LAGUNES D, ANTHONY LB, BERTINO $\mathrm{EM}, \mathrm{BRENDTRO} \mathrm{K}$, et al. Consensus guidelines for the management and treatment of neuroendocrine tumours. Pancreas 2013; 42: 557-577. http://dx.doi.org/10.1097/ MPA.0b013e31828e 34a 4

[19] Solcia E, Kloppel G, Sobin L. World Health Organization international histological Classification of tumors: Histological typing of endocrine tumours. 2nd ed. Berlin: Springer, 2000: 259. http://dx.doi.org/10.1007/978-3-642-59655-1

[20] OBERG K, CASTELLANO D. Current knowledge on diagnosis and staging of neuroendocrine tumors. Cancer Metastasis Rev 2011; 30: 3-7. http://dx.doi.org/10.1007/s10555-011$\underline{9292-1}$ 
[21] Rindi G, Arnold R, BOSMAN FT. Nomenclature and classification of neuroendocrine neoplasms of the digestive system. In: BOSMAN T, CARNEIRO F, HRUBAN R, THEISE N, eds. WHO classification of tumours of the digestive system, 4th edn. Lyon: International Agency for Research on cancer (IARC), 2010: 13-14.

[22] EKEBLAD S, SKOGSEID B, DUNDER K, OBERG K, ERIKSSON B. Prognostic factors and survival in 324 patients with pancreatic endocrine tumor treated at a single institution. Clin Cancer Res. 2008; 14: 7798-7803. http://dx.doi. org/10.1158/1078-0432.CCR-08-0734

[23] PANZUTO F, BONINSEGNA L, FAZIO N, CAMPANA D, PIA BRIZZI M, et al. Metastatic and locally advanced pancreatic endocrine carcinomas: analysis of factors associated with disease progression. J Clin Oncol. 2011; 29: 2372-2377. http://dx.doi.org/10.1200/JCO.2010.33.0688

[24] RINDI G, KLOPPEL G, ALHMAN H, CAPLIN M, COUVELARD A, et al. TNM staging of foregut (neuro)endocrine tumors: a consensus proposal including a grading system. Virchows Arch. 2006; 449: 395-401. http://dx.doi.org/10.1007/ s00428-006-0250-1

[25] STARKE A, SADDIG C, MANSFELD L, KOESTER R, TSCHAHARGANE C, et al. Malignant metastatic insulinoma postoperative treatment and follow-up. World J Surg 2005; 29: 789-793. http://dx.doi.org/10.1007/s00268-005-7743-y

[26] ZHAO YP, ZHAN HX, ZHANG TP, CONG L, DAI MH, et al. Surgical management of patients with insulinomas: Result of 292 cases in a single institution. J Surg Oncol 2010; 103(2): 169-174. http://dx.doi.org/10.1002/jso.21773

[27] ARNOLD R, WIED M, BEHR TH. Somatostatin analogues in the treatment of endocrine tumors of the gastrointestinal tract. Expert Opin Pharmacother 2002; 3: 643-656. http:// dx.doi.org/10.1517/14656566.3.6.643

[28] MATHUR A, GORDEN P, LIBUTTI SK. Insulinoma. Surg Clin North Am 2009; 89: 1105-1121. http://dx.doi.org/10.1016/j. suc.2009.06.009

[29] SARR MG. The potent somatostatin analogue vapreotide does not decrease pancreas-specific complications after elective pancreatectomy: a prospective, multicenter, double-blinded, randomized, placebo-controlled trial. J Am Coll Surg 2003; 196(4): 556-564. http://dx.doi.org/10.1016/S1072-7515(03)00104-2

[30] YEO CJ, CAMERON JL, LILLEMOE KD, SAUTER PK, COLEMAN J, et al. Does prophylactic octreotide decrease the rates of pancreatic fistula and other complications after pancreaticoduodenectomy? Results of a prospective randomized placebo-controlled trial. Ann Surg 2000; 232: 419-429. http:// dx.doi.org/10.1097/00000658-200009000-00014

[31] Korner M, Christ E, Wild D, REUBI JC. Glucagon-like peptide-1 receptor over expression in cancer and its impacton clinical applications. Front Endocrinol (Lausanne) 2012; 3: 158.

[32] SARMIENTO JM, QUE FG. Hepatic surgery for metastases from neuroendocrine tumors. Surg Oncol Clin N Am 2003; 12: 231-242. http://dx.doi.org/10.1016/S1055-3207(02)00076-5

[33] OSBORNE DA, ZERVOS EE, STROSBERG J, BOE BA, MALAFA M, et al. Improved outcome with cytoreduction versus embolization for symptomatic hepatic metastases of carcinoid and neuroendocrine tumors. Ann Surg Oncol. 2006; 13: 572-581. http://dx.doi.org/10.1245/ASO.2006.03.071

[34] HALFDANARSON TR, RABE KG, RUBIN J, PETERSEN GM. Pancreatic neuroendocrine tumors (PNETs): incidence, prognosis and recent trend toward improved survival. Ann. Oncol 2008 19: 1727-1733. http://dx.doi.org/10.1093/annonc/ $\underline{\operatorname{mdn} 351}$

[35] HAN X, XU XF, JIN DY, WANG DS, JI Y, et al. Clinicopathological characteristics and prognosis-related factors of resectable pancreatic neuroendocrine tumors. Pancreas 2014; 43: 526-531. http://dx.doi.org/10.1097/MPA.0000000000000065

[36] Soga J, Yakuwa Y, Osaka M. Insulinoma/hypoglycemic syndrome: a statistical evaluation of 1085 reported cases of a Japanese series. J Exp Clin Cancer Res 1998; 17: 379-388.

[37] DANFORTH DN JR, GORDEN P, BRENNAN MF. Metastatic insulin-secreting carcinoma of the pancreas: clinical course and the role of surgery. Surgery 1984; 96: 1027-1037. 